\title{
Impact of Hydrogen Bleeding into the Cathode Feed of a PEM Fuel Cell
}

\author{
Patrick Zihrul, a,b,* Philipp Weber, ${ }^{a}$ Julien Durst, ${ }^{a}$ Hubert A. Gasteiger, ${ }^{\text {a,** }}$ \\ and Frédéric Haschéa ${ }^{\mathrm{a}, * * *, \mathrm{z}}$
}

${ }^{a}$ Chair Technical Electrochemistry, Department of Chemistry and Catalysis Research Center,

Technische Universität München, D-85748 Garching, Germany

${ }^{b}$ Volkswagen AG, 38436 Wolfsburg, Germany

\begin{abstract}
Hydrogen bleeding into the cathode inlet of a proton exchange membrane (PEM) fuel cell could be a simple approach to reduce the $\mathrm{H}_{2}$ concentration in the fuel cell exhaust during transient operating conditions (e.g., start-up or fast transients) of a PEM fuel cell system; it could also serve as an additional heating source during cold start-up. In this experimental study, we address the question whether the chemical stability of the polymer electrolyte membrane is affected negatively by a hydrogen bleed into the cathode inlet of a PEM fuel cell. First, rotating ring disc electrode (RRDE) experiments were carried out to detect whether any additional $\mathrm{H}_{2} \mathrm{O}_{2}$ is produced during the oxygen reduction reaction in $\mathrm{O}_{2}$ saturated electrolytes in the absence and presence of $\mathrm{H}_{2}$. Dry open circuit voltage (OCV) experiments were then performed for more than 250 hours in $50 \mathrm{~cm}^{2}$ single cells at $120^{\circ} \mathrm{C}$ and $18 \%$ relative humidity (RH) in order to investigate the effect of a 4 vol. $\% \mathrm{H}_{2}$-bleed into the cathode inlet on membrane stability. Finally, the distribution of membrane pin-holes was determined on membrane electrode assemblies (MEAs) after the dry OCV tests conducted with or without $\mathrm{H}_{2}$-bleed using an infrared (IR) camera setup. In addition, the diffusion-limited hydrogen oxidation current on the cathode side was modeled in order to estimate the maximum areal heat flux near the cathode inlet, which would be caused if the $\mathrm{H}_{2}$ oxidation rate were to be diffusion-limited.

(C) The Author(s) 2017. Published by ECS. This is an open access article distributed under the terms of the Creative Commons Attribution Non-Commercial No Derivatives 4.0 License (CC BY-NC-ND, http://creativecommons.org/licenses/by-nc-nd/4.0/), which permits non-commercial reuse, distribution, and reproduction in any medium, provided the original work is not changed in any way and is properly cited. For permission for commercial reuse, please email: oa@electrochem.org. [DOI: 10.1149/2.0161704jes] All rights reserved.

(cc) BY-NC-ND
\end{abstract}

Manuscript submitted December 5, 2016; revised manuscript received January 9, 2017. Published January 24, 2017.

With the introduction of PEM (proton exchange membrane) based hydrogen fuel cell cars into the market, several government and state regulations have to be addressed, e.g., the global technical regulation on hydrogen and fuel cell vehicles which limits the exhaust gases (particularly non-consumed hydrogen) of a fuel cell car. ${ }^{1}$ Furthermore, due to safety reasons, the lower explosive limit of $4 \mathrm{vol}$. \% hydrogen in air has to be considered. During normal operating conditions, the nonconsumed hydrogen exiting the anode flow-field will be recirculated to the fuel cell system, ${ }^{2}$ with minute amounts of hydrogen exiting the anode loop. On the other hand, during cold start-up or fast load transients, substantial amounts of non-consumed hydrogen will exit the anode loop, in which case bleeding of the anode exit stream into to the cathode side inlet of the fuel cell stack could be a simple approach to meet the fuel cell system's $\mathrm{H}_{2}$ exhaust gas regulations. However, it is clear that this approach is limited to $<4$ vol. $\%$ hydrogen in air (i.e., well below the explosive limit) due to obvious safety reasons. Injecting $\mathrm{H}_{2}$ into the air inlet has already been described and was reported to be beneficial when it comes to removing residual water from the flowfield channels prior to shut-down of fuel cell stacks for subsequent freeze-start (i.e., preventing ice formation in the flow-field channels at sub-zero temperatures, which would lead to cell components damage) and to prevent cell flooding during start-up from low temperatures.

While $\mathrm{H}_{2}$-bleeding into the cathode feed clearly offers advantages for fuel cell system operation, it poses several questions regarding the long-term chemical and thermal stability of the membrane and the membrane electrode assembly (MEA), even though short-term degradation tests at normal operating conditions $\left(\leq 100 \mathrm{~h}\right.$ at $\left.80^{\circ} \mathrm{C}\right)$ did not indicate any problems: $:^{3,4}$ Does $\mathrm{H}_{2}$-bleed into the cathode feed lead to enhanced $\mathrm{H}_{2} \mathrm{O}_{2}$ production, which could accelerate polymer membrane degradation, resulting in membrane pin-holes and premature MEA failure? Does the injected $\mathrm{H}_{2}$ react homogeneously across the entire active area or does it react locally near the inlet region, in which case local hot-spots could lead to accelerated polymer membrane degradation?

\footnotetext{
*Electrochemical Society Student Member.

**Electrochemical Society Fellow.

****Electrochemical Society Member.

${ }^{\mathrm{z}}$ E-mail: frederic.hasche@tum.de
}

To address these questions, in the first part of this paper rotating ring disk electrode (RRDE) experiments in a liquid electrolyte cell were performed, by which the formation of $\mathrm{H}_{2} \mathrm{O}_{2}$ could be determined in the absence and presence of $\mathrm{H}_{2}$ in an $\mathrm{O}_{2}$-atmosphere in the potential range relevant for air cathode operation in a PEM fuel cell. The second part examines the effect of $\mathrm{H}_{2}$-dosing into the cathode feed on the long-term stability of MEAs tested in fuel cells. As an accelerated degradation test, dry open circuit voltage (OCV) experiments in $50 \mathrm{~cm}^{2}$ single cells were performed at $120^{\circ} \mathrm{C}$ and $18 \%$ relative humidity $(\mathrm{RH})$ with and without $\mathrm{H}_{2}$-bleeding into the cathode feed. Finally, computational simulation of the limiting hydrogen flux through the gas diffusion medium (GDL) were performed to estimate the diffusionlimited hydrogen consumption across the MEA, and the post-mortem pin-hole distribution of MEAs degraded with/without $\mathrm{H}_{2}$-bleed into the cathode feed was determined by an infrared camera setup.

\section{Experimental}

Rotating ring disk electrode (RRDE) measurements.-Rotating ring disk electrode (RRDE) experiments were carried out in a threeelectrode setup with a custom-made glass cell. A gold mesh was employed as counter electrode (CE), a reversible hydrogen electrode (RHE) as reference electrode (RE), and a interchangeable glassy carbon disk electrode (diameter $5 \mathrm{~mm}, 0.196 \mathrm{~cm}^{2}$ ) working electrode (WE) with a Pt ring (PINE Instruments). For thin-film electrode preparation, $10 \mu \mathrm{l}$ of the catalyst suspension were pipetted onto a freshly polished glassy carbon disk electrode and dried in an air stream, resulting in a loading of $21.5 \mu \mathrm{g}_{\mathrm{Pt}} \mathrm{cm}^{-2}$ geo. For the catalyst suspension, $5.6 \mathrm{mg}$ catalyst (37.7 wt\% Pt/C, TKK, TEC10V40E, Lot\#109-0441), $4.0 \mathrm{ml}$ de-ionized water $(18.2 \mathrm{M} \Omega \mathrm{cm}), 1 \mathrm{ml}$ 2-propanol (SigmaAldrich, \#650447-1L) and $20 \mu \mathrm{l}$ ionomer solution (Sigma-Aldrich, Nafion solution, $5 \mathrm{wt} \%$, \#274704-25 ML) were bath-sonicated for $20 \mathrm{~min}$. For each gas mixture, 5 voltammetric cycles were recorded between $0.06-1.10 \mathrm{~V}$ vs. RHE with $5 \mathrm{mV} \mathrm{s}^{-1}$ and 1600 rotation per minute (rpm). Prior to the experiments, the fresh electrolyte solution $\left(0.1 \mathrm{M} \mathrm{HClO}_{4}\right.$, prepared from $70 \% \mathrm{HClO}_{4}, 99.999 \%$ purity, GFS) was purged with the desired gas (5.0 purity) mixture (adjusted with two calibrated flow meters) for at least $20 \mathrm{~min}$. A potentiostat (Metrohm Autolab) and a PINE rotator were used for all RRDE measurements, which were conducted at room temperature. 
$50 \mathrm{~cm}^{2}$ single cell test and diagnostics. - Dry open circuit voltage $(O C V)$ test.-The dry OCV membrane stability tests were performed with $50 \mathrm{~cm}^{2}$ MEAs (PRIMEA MESGA, A510.1/M715.18/C580.4, $18 \mu \mathrm{m}$ membrane, catalyst loading $0.1 / 0.4 \mathrm{mg}_{\mathrm{Pt}} \mathrm{cm}^{-2}$ geo, W. L. Gore \& Associates $\mathrm{GmbH}$ ) and SGL 25 BC diffusion media (SGL Carbon $\mathrm{GmbH}$ ) at a compressive strain between $20-25 \%$ adjusted via PFTE coated fiber glass subgaskets. Fuel Cell Technologies Inc. cell hardware with POCO graphite serpentine flow-fields and a customdesigned G60 fuel cell test station (Greenlight Innovation Corp.) were used. The operating conditions for the dry OCV test were: cell temperature $120^{\circ} \mathrm{C}, 150 \mathrm{kPa}$ (abs.) inlet pressure, and inlet gas humidification of $18 \% \mathrm{RH}\left(74^{\circ} \mathrm{C}\right.$ dew point) at flow rates of $100 \mathrm{nccm}$ hydrogen at the anode and $100 \mathrm{nccm}$ air or $79 \mathrm{nccm} \mathrm{H}_{2}(5 \%) /$ Ar plus $21 \mathrm{nccm} \mathrm{O}_{2}$ at the cathode, which corresponds to $3.95 \% \mathrm{H}_{2}$ in $21 \% \mathrm{O}_{2}$ (rest $\mathrm{Ar}$ ). At least three measurements were done with $\mathrm{H}_{2}$-bleed into the cathode feed (labeled as MEA-1 to 3 ) and without $\mathrm{H}_{2}$-bleed as a reference case (labeled as MEA-4 to 7).

In-situ leak test.-During dry OCV stability tests, in-situ leak tests were performed every 5 hours. During these tests, the anode inlet pressure was increased from 150 to $180 \mathrm{kPa}$ (abs.), raising it $30 \mathrm{kPa}$ above the cathode pressure, and the corresponding change in cell voltage was measured. The voltage difference $\left(\Delta \mathrm{E}_{\Delta \mathrm{p}}\right)$ between $150 \mathrm{kPa}(\mathrm{abs}$. $)$ and $180 \mathrm{kPa}$ (abs.) anode pressure was used to indicate the formation of holes in the polymer membrane (see Results and Discussion section for further details).

Ex-situ leak test.-After the dry OCV tests, ex-situ leak tests were performed. For these, the cell was first shut down and cooled to room temperature, and the anode gas inlet as well as the cathode gas outlet of the cell were closed. Subsequently, with air through the $25^{\circ} \mathrm{C}$ humidifier a static pressure of $120 \mathrm{kPa}$ (abs.) was applied to the cathode inlet. Under these conditions, the gas exiting at the anode outlet derived from permeation through the membrane or/and membrane pin-holes was then collected over a defined period of time, thereby determining the gas leak rate (in $\mathrm{ml} \mathrm{minute}^{-1}$ ) through the MEA from the collected volume.

Determination of the location of membrane pin-holes.-In order to detect the positions of the pin-holes created in the membrane after each dry OCV test, the anode side of the MEA was fixed to a serpentine flow-field while the cathode side was open to ambient air. In a distance of $50 \mathrm{~cm}$ from the MEA surface, an infrared camera (P160 T250, IRIS Infrared Innovation Systems $\mathrm{GmbH}$ ) was installed in order to visualize the localized heat sources at the MEA surface, which are produced by the reaction of air with hydrogen leaking through membrane pinholes. Thus, after purging the anode side with $900 \mathrm{sccm}$ pure $\mathrm{N}_{2}$ for several minutes, the gas was switched to a mixture of $10 \% \mathrm{H}_{2} / \mathrm{N}_{2}(100$ $\mathrm{sccm} \mathrm{H}_{2}, 900 \mathrm{sccm} \mathrm{N_{2 }}$ ). The infrared images for the membrane pinhole distribution analysis were taken roughly $30 \mathrm{~s}$ after the hydrogen entered the flow-field. All measured MEAs were installed so that the inlet and outlet were in the same positions in the flow-field as during the dry OCV tests.

\section{Results and Discussion}

Hydrogen peroxide formation in hydrogen/oxygen atmosphere.-To detect whether any additional hydrogen peroxide is produced during the oxygen reduction reaction (ORR) due to $\mathrm{H}_{2}$-bleed into oxygen, rotating ring disk electrode (RRDE) experiments were performed. The lower panel of Figure 1 shows the steady-state polarization curves (positive-going scans) recorded when bubbling either pure $\mathrm{O}_{2}$ (blue curve), pure $\mathrm{H}_{2}$ (red curve), or $\mathrm{H}_{2} / \mathrm{O}_{2}$ mixtures (black and green curves) through the RRDE cell. The upper panel of Figure 1 shows the corresponding ring currents recorded at $1.2 \mathrm{~V}$ vs. RHE (for the oxygen-containing gas mixtures) which are baseline corrected by subtracting the small and disk-potential-independent hydrogen oxidation reaction (HOR) related ring current for each gas mixture (note that the HOR currents

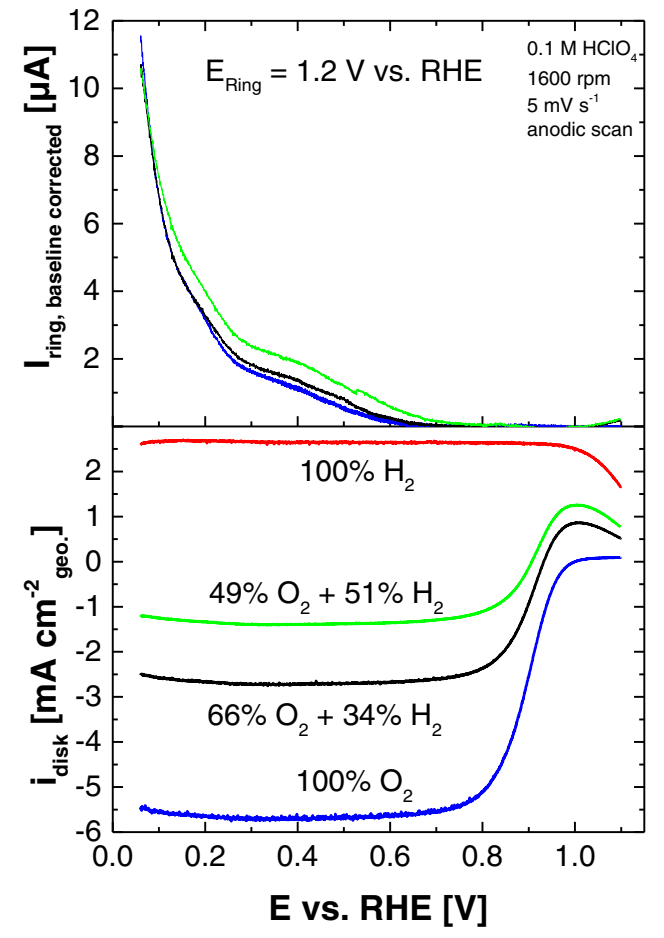

Figure 1. Rotating ring disk electrode (RRDE) measurements on $\mathrm{Pt} / \mathrm{C}$ in 0.1 $\mathrm{M} \mathrm{HClO}_{4}$ conducted with various ratios of hydrogen/oxygen feed gases bubbling through the electrolyte. The ring current (upper panel) was detected on a pure Pt-ring at constant voltage ( $1.2 \mathrm{~V}$ vs. RHE) and is baseline corrected by the small and disk-potential-independent HOR current on the Pt-ring. The geometric area based current density (lower panel) was measured on the catalystcoated glassy carbon disk during the linear voltage scan with $5 \mathrm{mV} \mathrm{s}^{-1}$ (the positive-going steady-state polarization curves are shown in the figure). Conditions: room temperature, rotation rate of $1600 \mathrm{rpm}$, disk area $0.196 \mathrm{~cm}^{2}$, catalyst loading $21.5 \mu \mathrm{g}_{\mathrm{Pt}} \mathrm{cm}^{-2}$ geo, potential range of $0.06-1.10 \mathrm{~V}$ vs. RHE.

on the Pt-ring at the ring potential of $1.2 \mathrm{~V}$ vs. RHE are only $\approx 3 \mu \mathrm{A}$ for pure $\mathrm{O}_{2}$ due to the low HOR activity of $\mathrm{Pt}$ at high potentials ${ }^{5}$ ); from the baseline corrected ring currents, the amount of hydrogen peroxide during the ORR can be determined.

With pure oxygen (Figure 1, lower panel, blue curve), a typical oxygen polarization curve is observed. For all measured gas compositions, diffusion-limited voltage plateaus between $\approx 0.2$ and $\approx 0.7 \mathrm{~V}$ vs. RHE can be seen, where the diffusion of the reacting gas is the rate limiting process. The measured diffusion-limiting current density $\left(\mathrm{i}_{\lim }\right)$ is $-5.71 \mathrm{~mA} \mathrm{~cm}^{-2}$ geo. with pure $\mathrm{O}_{2}$ (blue curves, Figure 1) and $+2.69 \mathrm{~mA} \mathrm{~cm}^{-2}$ geo. with pure $\mathrm{H}_{2}$ (red curve, lower panel of Figure 1). In the presence of both $\mathrm{H}_{2}$ and $\mathrm{O}_{2}$ and assuming that the reaction pathway of each gas is not affected by the presence of the other, the diffusion-limited current density would have to be directly proportional to the relative sum of the diffusion-limiting current densities of the HOR and the ORR, as described in Eq. 1.

$$
\mathrm{i}_{\text {lim, } \mathrm{x} \% \mathrm{O}_{2}+\mathrm{y} \% \mathrm{H}_{2}}=\left(\mathrm{x} \% \cdot \mathrm{i}_{\lim , 100 \% \mathrm{O}_{2}}\right)+\left(\mathrm{y} \% \cdot \mathrm{i}_{\text {lim, }, 100 \% \mathrm{H}_{2}}\right)
$$

Based on the measured values for $100 \% \mathrm{H}_{2}$ and $100 \% \mathrm{O}_{2}$, the calculated diffusion-limiting current densities for the gas mixtures $\left(66 \% \mathrm{O}_{2}+34 \% \mathrm{H}_{2}\right.$ as well as $\left.49 \% \mathrm{O}_{2}+51 \% \mathrm{H}_{2}\right)$ are $-2.86 \mathrm{~mA}$ $\mathrm{cm}^{-2}{ }_{\text {geo }}$ and $-1.43 \mathrm{~mA} \mathrm{~cm}^{-2}{ }_{\text {geo }}$, respectively. These calculated values are in excellent agreement with the experimentally measured values of $-2.72 \mathrm{~mA} \mathrm{~cm}^{-2}$ geo. and $-1.38 \mathrm{~mA} \mathrm{~cm}^{-2}$ geo, suggesting that the HOR and the ORR kinetics are not affected by the presence of the other reactant (the deviation of less than $5 \%$ is related to the accuracy of adjusting the gas mixtures).

The upper panel of Figure 1 shows the baseline corrected ring current during a positive-going linear potential sweep of the disk electrode coated with a thin-film catalyst layer, enabling the detection 
of $\mathrm{H}_{2} \mathrm{O}_{2}$ produced on the disk by its subsequent oxidation on the Pt-ring held at $1.2 \mathrm{~V}$ vs. RHE. Comparing the ring currents for pure $\mathrm{O}_{2}$ with that obtained in the $66 \% \mathrm{O}_{2}+34 \% \mathrm{H}_{2}$ mixture (blue vs. black curve in the upper panel of Figure 1), it is quite clear that the $\mathrm{H}_{2} \mathrm{O}_{2}$ formation at the disk electrode during the ORR is not affected by the presence of $\mathrm{H}_{2}$ : no $\mathrm{H}_{2} \mathrm{O}_{2}$ current is observed above $\approx 0.6 \mathrm{~V}$, while the gradual ring current increase with decreasing potential below $\approx 0.6 \mathrm{~V}$ which is well known from the literature ${ }^{6}$ is identical for both pure $\mathrm{O}_{2}$ and $66 \% \mathrm{O}_{2}+34 \% \mathrm{H}_{2}$. While the ring currents below $\approx 0.7 \mathrm{~V}$ are slightly higher in the $49 \% \mathrm{O}_{2}+51 \% \mathrm{H}_{2}$ mixture (green curve in the upper panel of Figure 1) compared to pure $\mathrm{O}_{2}$, the overall currents are still extremely low. Therefore, up to a $\mathrm{H}_{2} / \mathrm{O}_{2}$ ratio of $1 / 2$ (corresponding to $66 \% \mathrm{O}_{2}+34 \% \mathrm{H}_{2}$ ), the extent of $\mathrm{H}_{2} \mathrm{O}_{2}$ formation during the ORR is not affected by the presence of $\mathrm{H}_{2}$, so that our RRDE analysis strongly suggests that bleeding of up to $4 \% \mathrm{H}_{2}$ into the cathode air feed $\left(21 \% \mathrm{O}_{2}\right)$ should not lead to increased $\mathrm{H}_{2} \mathrm{O}_{2}$ formation in the fuel cell cathode. In summary, up to $\mathrm{H}_{2}$ concentrations relevant for the $\mathrm{H}_{2}$-bleed into the cathode compartment $\left(\leq 4 \% \mathrm{H}_{2}\right)$, the change in the diffusion-limiting current density and the equivalence of the $\mathrm{H}_{2} \mathrm{O}_{2}$ formation suggest that the ORR pathway is not changed.

For comparison, the effect of bleeding oxygen in an $\mathrm{H}_{2}$-atmosphere on the anode side of a PEM fuel cell is already well known and reported in the literature. ${ }^{7}$ It enables the electrooxidation of $\mathrm{CO}$ adsorbed on the anode catalyst surface to $\mathrm{CO}_{2}$, thereby mitigating the adverse effect of $\mathrm{CO}$ impurities in $\mathrm{H}_{2}$ fuel. ${ }^{8-10}$ Here, the critical issue is an increased formation of hydrogen peroxide caused by the $\mathrm{O}_{2}$-bleed (indicated by the increased $\mathrm{H}_{2} \mathrm{O}_{2}$ formation at low potentials shown in the upper panel of Figure 1), which in turn reacts with Fenton's active ions in the membrane (e.g., $\mathrm{Fe}^{2+}$ ) and finally leads to faster polymer membrane degradation. ${ }^{11}$ Clearly, the difference between bleeding $\mathrm{O}_{2}$ into the anode $\mathrm{H}_{2}$-feed to mitigate $\mathrm{CO}$ poisoning versus bleeding $\mathrm{H}_{2}$ into the cathode air-feed, is that in the former case the presence of $\mathrm{O}_{2}$ in the anode $\mathrm{H}_{2}$-feed leads to substantial $\mathrm{H}_{2} \mathrm{O}_{2}$ formation from the ORR in the anode potential range $(\approx 0-0.05 \mathrm{~V}$ vs. RHE), while in the latter case the presence of $\mathrm{H}_{2}$ in the air-feed does not affect the extent of $\mathrm{H}_{2} \mathrm{O}_{2}$ formation in the cathode potential range $(\approx 0.6-1 \mathrm{~V}$ vs. RHE). This leads to the different chemical degradation mechanism for the polymer membrane, where in the case of $\mathrm{O}_{2}$-bleed into the anode $\mathrm{H}_{2}$ feed an accelerated chemical degradation of the polymer membrane is observed. ${ }^{11}$

$50 \mathrm{~cm}^{2}$ single cell dry OCV membrane stability test.-While the RRDE experiments allow to exclude the possibility of additional $\mathrm{H}_{2} \mathrm{O}_{2}$ formation in the presence of a $\mathrm{H}_{2}$-bleed into the cathode air, possible local heating of the MEA due to possibly localized $\mathrm{H}_{2}$ oxidation near the cathode inlet cannot be excluded. Therefore, $50 \mathrm{~cm}^{2}$ single cell experiments were conducted under dry OCV conditions $\left(120^{\circ} \mathrm{C}, 18 \%\right.$ $\mathrm{RH}, 150 \mathrm{kPa}$ (abs.) for $\mathrm{H}_{2}$ and air at $100 \mathrm{nccm}$ flows) without and with $\approx 4 \% \mathrm{H}_{2}$ being bled into the cathode feed containing $21 \% \mathrm{O}_{2}$. The experiments were conducted until the appearance of membrane pin-holes, which were detected by an increase of the OCV drop when raising the anode pressure $30 \mathrm{kPa}$ above the cathode pressure (was done every 5 hours for $\approx 5$ minutes). The basic principle of this pinhole detection method is described in the following.

The expected open circuit voltage difference measured at balanced pressure (150/150 $\mathrm{kPa}$ (abs.) anode/cathode) and at anode over pressure $\left(180 / 150 \mathrm{kPa}\right.$ (abs.) anode/cathode), $\Delta \mathrm{E}_{\Delta \mathrm{p}}$, is illustrated in Figure 2 in the case of a pin-hole free MEA. In this case, $\Delta \mathrm{E}_{\Delta \mathrm{p}}$ depends only on the difference in the applied hydrogen partial pressure on the anode side, since the partial pressure controlled $\mathrm{H}_{2}$-crossover current $\left(\mathrm{i}_{\mathrm{H}_{2} \text {-cross }}\right)$ through the membrane affects the $\mathrm{OCV}$, as explained in the following. First we discuss the standard case without $\mathrm{H}_{2}$-bleed. Here, the measured $\mathrm{i}_{\mathrm{H}_{2} \text {-cross }}$ at the given reaction conditions $\left(120^{\circ} \mathrm{C}, 18 \%\right.$ $\mathrm{RH}, 150 / 150 \mathrm{kPa}$ (abs.) anode/cathode) is $3.4 \mathrm{~mA} \mathrm{~cm}^{-2}$ MEA (blue dotted vertical line in Figure 2). Considering that the OCV is the result of a mixed potential where the oxygen reduction rate is balanced by the hydrogen oxidation rate. The predicted $\mathrm{OCV}$ at a $\mathrm{H}_{2}$ permeation rate of $3.4 \mathrm{~mA} \mathrm{~cm}^{-2}$ MEA is the potential at which the $\mathrm{H}_{2}$ oxidation current is balanced by the ORR current, which can be estimated by the

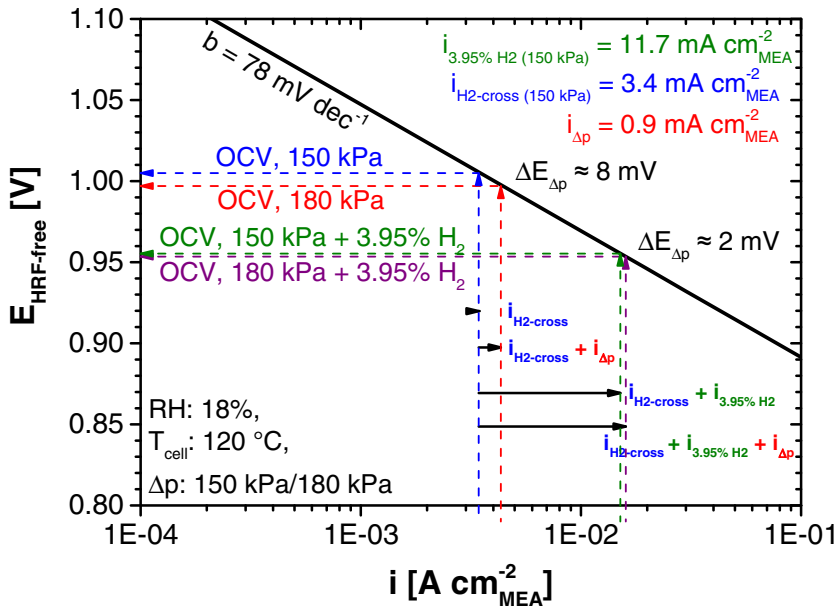

Figure 2. Predicted open circuit voltage (OCV) difference $\left(\Delta \mathrm{E}_{\Delta \mathrm{p}}\right)$ upon increase of the anode pressure from 150 to $180 \mathrm{kPa}($ abs.) in the absence of membrane pin-holes, i.e., in the case of purely permeation limited $\mathrm{H}_{2}$-crossover. These estimates are based on the ORR kinetic data from Reference 12 and on the following OCV test conditions: cathode pressure of $150 \mathrm{kPa}$ (abs.) using a cathode feed with $21 \% \mathrm{O}_{2}$ at $120^{\circ} \mathrm{C}, 18 \% \mathrm{RH}$.

known ORR kinetics of the catalyst ${ }^{12}$ shown by the solid black line in Figure 2. The thus predicted OCV at $150 / 150 \mathrm{kPa}$ (abs.) anode/cathode is $1.006 \mathrm{~V}$. An increase of the anode pressure to $180 \mathrm{kPa}($ abs.) will increase the $\mathrm{H}_{2}$-crossover current by $\mathrm{i}_{\Delta \mathrm{p}} \approx 0.9 \mathrm{~mA} \mathrm{~cm}{ }^{-2}$ MEA (red dotted line in Figure 2), i.e., by a factor of $\approx 1.26$, as calculated by Eq. 1.

$$
i_{\Delta p}=\frac{180 k P a(\text { abs. })-\left(\text { relative humidity } \cdot p_{H_{2} \mathrm{O}}^{\text {sat. }}\right)}{150 k P a(\text { abs. })-\left(\text { relative humidity } \cdot p_{H_{2} \mathrm{O}}^{\text {sat. }}\right)}
$$

As illustrated in Figure 2, the increased $\mathrm{H}_{2}$-crossover current upon increasing the anode pressure from 150 to $180 \mathrm{kPa}$ (abs.) should result in an OCV drop of $\Delta \mathrm{E}_{\Delta \mathrm{p}} \approx 8 \mathrm{mV}$.

Now let us examine the OCV behavior in the presence of an $\mathrm{H}_{2}$ bleed into the cathode feed. When introducing $3.95 \mathrm{nccm}_{2}$ into the cathode feed, an additional (parasitic) HOR current of $\mathrm{i}_{3.95 \% \mathrm{H}_{2}}=11.7$ $\mathrm{mA} \mathrm{cm}{ }^{-2}$ MEA will be added to the $\mathrm{H}_{2}$-crossover current of $3.4 \mathrm{~mA}$ $\mathrm{cm}^{-2}$ MEA at an anode pressure of $150 \mathrm{kPa}(\mathrm{abs}$.), which is predicted to lower the $\mathrm{OCV}$ to $\approx 0.955 \mathrm{~V}$ under these conditions (green dotted line in Figure 2). In this case, the increase of the $\mathrm{H}_{2}$-crossover current by $\mathrm{i}_{\Delta \mathrm{p}} \approx 0.9 \mathrm{~mA} \mathrm{~cm}{ }^{-2} \mathrm{MEA}$ when increasing the anode pressure to $180 \mathrm{kPa}$ (abs.) results in a much lower but still significant OCV drop of $\Delta \mathrm{E}_{\Delta \mathrm{p}} \approx 2 \mathrm{mV}$ (purple dotted line in Figure 2).

In summary, in the absence of membrane pin-holes, an increase of the anode pressure from 150 to $180 \mathrm{kPa}$ (abs.) is estimated to result in an OCV drop of $\approx 8 \mathrm{mV}$ in the absence of an $\mathrm{H}_{2}$-bleed and of $\approx 2 \mathrm{mV}$ with $\approx 4 \% \mathrm{H}_{2}$-bleed. Once membrane pin-holes have formed, a positive pressure differential between anode and cathode will result in a substantially increased $\mathrm{H}_{2}$-crossover due to pressure-driven $\mathrm{H}_{2}$ flow from the anode to the cathode, which in turn should result in a substantial increase of the OCV drop, $\triangle \mathrm{E}_{\Delta \mathrm{p}}$, and thus allow for the in-situ detection of membrane pin-holes during the dry OCV test. That this is indeed the case will be shown below.

Figure 3 shows the recorded open circuit voltage during the dry OCV membrane stability test at $120^{\circ} \mathrm{C}$ and $18 \% \mathrm{RH}$ for the various MEAs with $\mathrm{H}_{2}$-bleed (black lines, MEA-1 to 3) and without $\mathrm{H}_{2}$ bleed (red lines, MEA-4 to 7) into the cathode inlet gas. The initial OCV values under these harsh membrane degrading conditions are $\approx 0.96 \pm 0.01 \mathrm{~V}$ for the four MEAs operated without an $\mathrm{H}_{2}$-bleed into the cathode inlet (red lines in Figure 3), which is reasonably close to the estimated dry OCV value of $\approx 1.0 \mathrm{~V}$ (see Figure 2 ). Similarly, the initial dry OCV values $\approx 0.92 \mathrm{~V}$ for the two MEAs with $\mathrm{H}_{2}$-bleed of (MEA-2 and 3, black lines in Figure 3) is close to the 


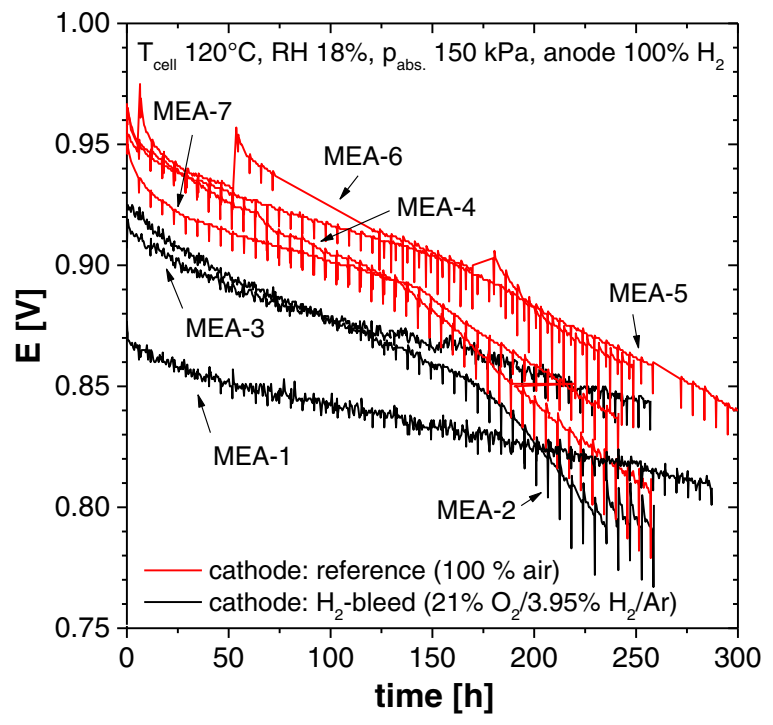

Figure 3. Open circuit voltage at $120^{\circ} \mathrm{C}, 18 \% \mathrm{RH}$ and $150 \mathrm{kPa}(\text { abs. })_{\text {cathode }} \mathrm{vs}$. time for the various measured MEAs with $\mathrm{H}_{2}$-bleed (black lines, MEA-1 to 3 ) and without $\mathrm{H}_{2}$-bleed (red lines, MEA-4 to 7) into the cathode feed gas. The cathode inlet flows are $100 \mathrm{nccm}$ air in the absence of an $\mathrm{H}_{2}$-bleed and $79 \mathrm{nccm}$ $\mathrm{H}_{2}(5 \%) /$ Ar plus $21 \mathrm{nccm} \mathrm{O}_{2}$ in the presence of an $\mathrm{H}_{2}$-bleed; the anode inlet flow is $100 \mathrm{nccm}$ at an inlet pressure of $150 \mathrm{kPa}($ abs.), with a short temporary increase to $180 \mathrm{kPa}($ abs.) every 5 hours, resulting in temporary OCV drops, $\Delta \mathrm{E}_{\Delta \mathrm{p}}$.

estimated value of $\approx 0.95 \mathrm{~V}$ (see Figure 2); unfortunately, the origin for the substantially lower dry OCV value of MEA-1 is not understood and could be explained by deviation in e.g. MEA manufacturing or cell assembly. The relatively fast decay of the dry OCV value with time for all MEAs is consistent with the observations by Zhang et al., ${ }^{13}$ where it was shown to be due to rapid ionomer degradation under dry OCV conditions, leading to sulfate induced poisoning of the oxygen reduction reaction. They also showed that this decay is partially reversible under conditions where liquid water is present in the MEA, allowing the removal of sulfate ions from the cathode electrode. This can be seen in the OCV trace of MEA-6 (see Figure 2), for which the initial OCV of $\approx 0.96 \mathrm{~V}$ drops toward $\approx 0.93 \mathrm{~V}$ after $\approx 50$ $\mathrm{h}$, at which time an unintended shut-down occurred; after start-up of the cell from room temperature, the OCV recovered to essentially its initial value.

More essential for our detection of membrane pin-holes, however, is the OCV drop upon increasing the anode pressure by $30 \mathrm{kPa}$ over the cathode pressure (see Experimental section): according to the discussion of Figure 2, the pressure induced OCV drop, $\triangle \mathrm{E}_{\Delta \mathrm{p}}$, for a pin-hole free membrane should amount to $\approx 8 \mathrm{mV}$ and $\approx 2 \mathrm{mV}$ in the absence and presence of an $\mathrm{H}_{2}$-bleed into the cathode inlet, respectively. Inspecting the voltage spikes upon anode over-pressurization conducted every five hours for the MEAs operated without an $\mathrm{H}_{2}$ bleed (red lines in Figure 3), the initially observed voltage drop is indeed in the predicted range of $\Delta \mathrm{E}_{\Delta \mathrm{p}} \approx 8 \mathrm{mV}$. In the presence of an $\mathrm{H}_{2}$-bleed (black lines in Figure 3), the predicted voltage drop upon anode over-pressurization of $\Delta \mathrm{E}_{\Delta \mathrm{p}} \approx 2 \mathrm{mV}$ is not clearly visible in Figure 3, but is quite apparent in Figure 4 , where the values of $\Delta \mathrm{E}_{\Delta \mathrm{p}}$ vs. time are shown. As guide to the eye, the calculated $\Delta \mathrm{E}_{\Delta \mathrm{p}}$ values predicted by the analysis in Figure 2 are indicated in Figure 4 for MEAs operated without $\mathrm{H}_{2}$-bleed (red dashed line) and with $\mathrm{H}_{2}$-bleed (black dashed line) into the cathode inlet. Quite clearly, there is a surprisingly good agreement between the initially measured $\Delta \mathrm{E}_{\Delta \mathrm{p}}$ values and those predicted by the analysis in Figure 2, supporting our initial assumption that the OCV drop upon anode over-pressurization for a pin-hole free membrane is simply related to an increased hydrogen permeation.

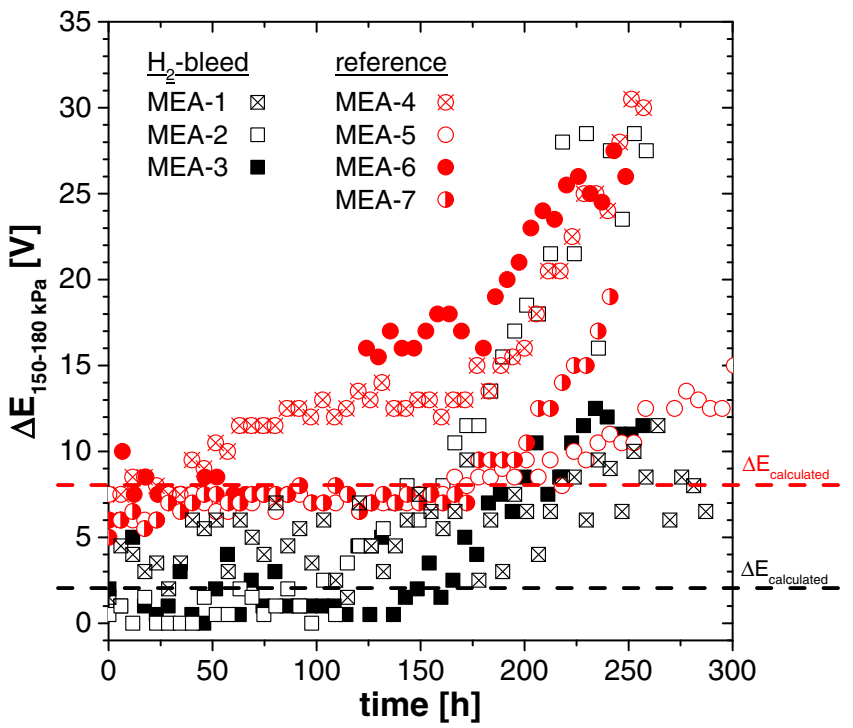

Figure 4. In-situ leak test during the dry OCV membrane stability test in the absence (MEA-4 to 7; red symbols) and presence (MEA-1 to 3; black symbols) of $\mathrm{H}_{2}$-bleed into the cathode feed, showing the voltage difference $\left(\Delta \mathrm{E}_{\Delta \mathrm{p}}\right)$ between $150 \mathrm{kPa}$ (abs.) and $180 \mathrm{kPa}$ (abs.) anode inlet pressure vs. time. The data are extracted from Figure 3 and the dotted lines represent the OCV drops, $\Delta \mathrm{E}_{\Delta \mathrm{p}}$, predicted by the analysis shown in Figure 2.

During the first $\approx 50$ hours of the dry OCV test, the $\Delta \mathrm{E}_{\Delta \mathrm{p}}$ values of all tested MEAs remain constant near the predicted $\Delta \mathrm{E}_{\Delta \mathrm{p}}$ (Figure 4) and then increase gradually until about 150 hours, which we believe is due to a continuous thinning of the membrane with a concomitant increase of the $\mathrm{H}_{2}$ permeation rate, caused by the fast ionomer degradation under dry OCV conditions at high temperature. ${ }^{13-15}$ Above $\approx 150$ hours, the $\Delta \mathrm{E}_{\Delta \mathrm{p}}$ values of all MEAs increase at an accelerating rate, indicating the beginning of membrane pin-hole formation, independent of whether $\mathrm{H}_{2}$ is being bled into the cathode inlet or not.

In order to confirm the in-situ leak data obtained by the analysis of the OCV drop upon anode over-pressurization, the ex-situ leak rates (see Experimental section) of all MEAs were measured after the dry OCV tests and the location of pin-holes were determined via the infrared camera test. Figure 5 shows the ex-situ determined leak rates

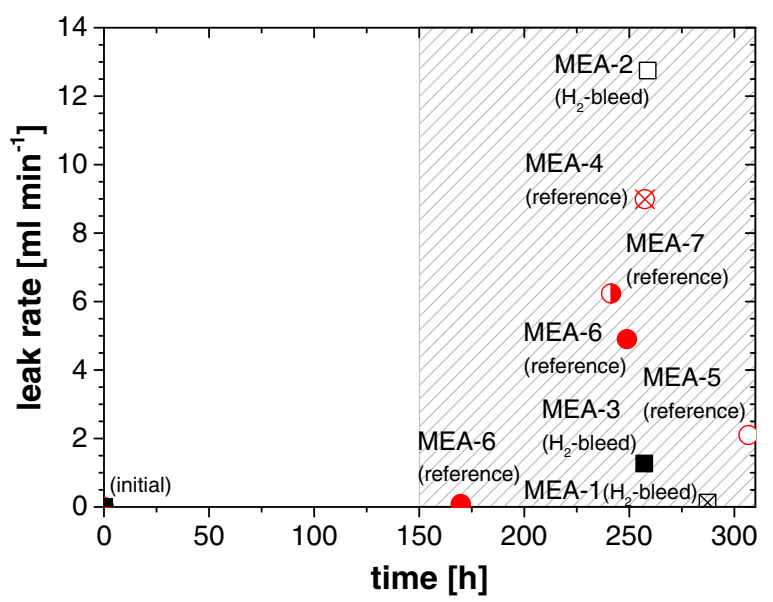

Figure 5. Ex-situ leak tests conducted at room temperature (see Experimental section) after the dry OCV membrane stability tests shown in Figures 3 and 4 for MEAs tested without $\mathrm{H}_{2}$-bleed (MEA-4 to 7; red symbols) and with $\mathrm{H}_{2}$-bleed (MEA-1 to 3; black symbols) into the cathode inlet. Note that the ex-situ leak of MEA- 6 was determined both before and after the onset of the accelerated increase of the OCV drop, $\Delta \mathrm{E}_{\Delta \mathrm{p}}$, (solid red circle at $\approx 170 \mathrm{~h}$ and $\approx 250 \mathrm{~h}$, respectively) in order to confirm the validity of the test. 
after the dry OCV test, i.e., after a rapid increase of the OCV drop upon anode over-pressurization was observed. Let us first examine MEA-6 (reference case without $\mathrm{H}_{2}$-bleed into the cathode inlet), for which the ex-situ leak test was conducted both before (at $\approx 170 \mathrm{~h}$ ) and after $($ at $\approx 250 \mathrm{~h}$ ) the accelerated increase in the OCV drop was noted: a leak rate above the permeation rate through a pin-hole free membrane was only observed once an acceleration of the OCV drop was detected, confirming the validity of the in-situ measurement. With the exception of MEA-1, all other MEAs which were examined after they had exhibited an accelerated increase of the OCV drop showed a pronounced leak in the ex-situ leak test. MEA-1 did not show the expected ex-situ leak, which we believe is related to the closing of small pin-holes caused by the expansion of the membrane upon water uptake (i.e., swelling) occurring in the presence of condensed liquid water at room temperature (note that the $\Delta \mathrm{E}_{\Delta \mathrm{p}}$ value of MEA-1 had only increased by $\approx 5 \mathrm{mV}$ compared to $>>10 \mathrm{mV}$ for the other MEAs by the end of the dry OCV test; see Figure 4). Nevertheless, Figure 5 reflects the conclusions drawn from Figure 4, namely that there is no correlation between the onset of membrane pin-hole formation with the presence or absence of an $\mathrm{H}_{2}$-bleed into the cathode inlet, consistent with the observation that the extent of $\mathrm{H}_{2} \mathrm{O}_{2}$ formation is not impacted by the $\mathrm{H}_{2}$-bleed (see Figure 2).

Computation of the diffusion-limited hydrogen flux through the gas diffusion layer (GDL).-One of the consequences of bleeding hydrogen into the cathode inlet in the above conducted dry OCV test is that the oxidation of hydrogen with oxygen to water, catalyzed by the platinum catalyst in the cathode, might be so fast, that the hydrogen oxidation reaction could proceed at a diffusion-limited rate, i.e., would be controlled by the diffusion of hydrogen from the channel/GDL interface to the GDL/electrode interface. With the following alongthe-channel model we will estimate the diffusion-controlled rate of hydrogen from the channel to the electrode, using it to estimate the concentration profile of hydrogen along the cathode channel and the additional local areal heat flux.

Along-the-channel model for the diffusion-limited $\mathrm{H}_{2}$ consumption.-To estimate the $\mathrm{H}_{2}$ concentration along the cathode channel when $\mathrm{H}_{2}$ is bled into the cathode inlet under the assumption that the consumption of $\mathrm{H}_{2}$ is purely limited by its diffusion from the channel/GDL interface to the GDL/electrode interface, an along-thechannel steady-state $1 \mathrm{D}$-diffusion model was used. This model calculates the diffusion-limited hydrogen flux $\dot{J}_{\mathrm{H}_{2}, \text { lim }}$ (in units of mol cm $\mathrm{cm}^{-2}$ $\mathrm{s}^{-1}$ ) for each segment along-the-channel. In every segment the amount of hydrogen diffusing to the catalyst layer is computed by the limiting hydrogen flux based on the hydrogen concentration in the channel. Here, the reaction is assumed to occur at the very GDL/electrode interface, i.e., the oxidation of $\mathrm{H}_{2}$ at the cathode is assumed to be much faster compared to the diffusional transport of $\mathrm{H}_{2}$ across the GDL. The limiting flux of hydrogen in the z-direction (i.e., in the direction normal to the GDL) is calculated by using the Maxwell-Stefan diffusion equations, assuming a constant pressure in the GDL: ${ }^{16}$

$$
\frac{\partial \mathrm{x}_{\mathrm{i}}}{\partial \mathrm{z}}=-\sum_{\mathrm{j} \neq \mathrm{i}}^{\mathrm{n}} \frac{\mathrm{x}_{\mathrm{j}} \cdot \dot{J}_{i}-\mathrm{x}_{\mathrm{i}} \cdot \dot{J}_{j}}{\mathrm{c} \cdot \mathrm{D}_{\mathrm{ij}}}
$$

where $x_{i}$ is the mole fraction of species $i$ along the z-direction (i.e., across the GDL) in the presence of all other species $j, \dot{J}_{i}$ is the molar flux of species $i, c$ is the overall concentration of all species (in units of $\mathrm{mol} \mathrm{cm}-3$ ), and $D_{i j}$ is the binary diffusion coefficient (in units of $\mathrm{cm}^{2} \mathrm{~s}^{-1}$ ). The latter are calculated with the following relation and the parameters taken from Reference 16-18:

$$
D_{i j}=0.0018583 \cdot \sqrt{T^{3} \cdot\left(\frac{1}{M_{i}}+\frac{1}{M_{j}}\right) \frac{1}{P \cdot \sigma_{i j}^{2} \cdot \Omega_{i j}}}
$$

with:

$$
\Omega_{i j}=\frac{1.06063}{T^{* 0.15610}}+\frac{0.19300}{e^{\left(0.47635 \cdot T^{*}\right)}}+\frac{1.03587}{e^{\left(1.52996 \cdot T^{*}\right)}}+\frac{1.76474}{e^{\left(3.89411 \cdot T^{*}\right)}} ;
$$

$$
\begin{gathered}
T^{*}=\frac{k_{B} \cdot T}{\varepsilon_{i j}} ; \\
\sigma_{i j}=\frac{1}{2} \cdot \sqrt{\sigma_{i}+\sigma_{j}} \text { and } \\
\varepsilon_{i j}=\sqrt{\varepsilon_{i} \cdot \varepsilon_{j}}
\end{gathered}
$$

where $T$ is the temperature in Kelvin, $M_{i}$ is the molecular mass of species $i, P$ is the total pressure, and all the other parameters are specified in the List of Symbols. The binary diffusion coefficients $D_{i j}$ are corrected for the effective diffusion through a porous media $\left(D_{\text {eff }}\right)$ with the Bruggeman approximation, ${ }^{19,20}$ assuming constant throughplane properties for the GDL and the MPL with a porosity $\varepsilon=66 \%$.

$$
\frac{D_{i j}}{D_{e f f}}=\varepsilon^{-1,5}
$$

The Maxwell-Stefan diffusion equation (Eq. 3) is solved with the following boundary conditions (Eq. 6), which set the molar fractions of all species at the channel/GDL interface $(z=0)$ to the local channel concentration and specify that the hydrogen concentration at the catalyst/GDL interface $\left(z=t_{G D L}\right)$ is zero in the here considered diffusionlimited reaction rate of $\mathrm{H}_{2}$. In that case, the resulting hydrogen flux, $\dot{J}_{H_{2}}$, is equal to the limiting hydrogen flux, $\dot{J}_{H_{2, \text { lim }}}$. In this model only the OCV case, no electrical current is generated, is considered. Thus the oxygen flux through the GDL, $\dot{J}_{O_{2}}$, is equal to half the hydrogen flux.

$$
\begin{aligned}
& x_{(i)}(z=0)=x_{(i)}(\text { Channel }) ; \\
& x_{H_{2}}\left(z=t_{G D L}\right)=0 ; \\
& \dot{J}_{O_{2}}=0.5 \cdot \dot{J}_{H_{2}} ; \\
& \dot{J}_{H_{2} O}=-\dot{J}_{H_{2}} ; \\
& \dot{J}_{k}=0 ; \mathrm{k}=\mathrm{N}_{2}, \mathrm{Ar}
\end{aligned}
$$

With the thus calculated limiting hydrogen flux, $\dot{J}_{H_{2, \text { lim }}}$, the limiting hydrogen current, $i_{l i m, H_{2}}$, can be calculated according to:

$$
i_{\text {lim }, H_{2}}=\dot{J}_{H_{2, l i m}} \cdot 2 \cdot F
$$

The resulting limiting hydrogen current density and the length of the reaction zone for the hydrogen oxidation reaction on the cathode side can now be estimated using an along-the-channel approach. Here we consider the combined area of three channels, where every channel has a width of $2 \mathrm{~mm}$. The active area is segmented in $1 \mathrm{~mm}$ steps alongthe-channel, resulting in $6 \mathrm{~mm}^{2}$ areas $(1 \mathrm{~mm}$ length and width of $6 \mathrm{~mm})$. It is assumed that the gases are perfectly mixed within each segment. Furthermore, all diffusion and reactions are assumed to be taking place only above the channel area, i.e., assuming no diffusion or reaction under the flow-field landings which are not considered in this study. Figure 6 shows the along-the-channel model with the geometric settings and the molar balances which were used.

For the incoming gases, the molar flow rates are calculated based on the operating conditions (gas flow, relative humidity, temperature and hydrogen concentration). The percentage of hydrogen is based on the molar dry gas mixture. Table I shows the molar balances used for the computational simulations.

For the calculation of the water saturation pressure at the inlet, Eq. 8 is used:

$$
\begin{aligned}
\log \left(p_{\text {sat }}\right)= & -2.7194+2.9535 \cdot 10^{-2} \cdot T \\
& -9.1838 \cdot 10^{-5} \cdot T^{2}+1.4454 \cdot 10 \cdot T^{3}
\end{aligned}
$$

where $T$ is the temperature in Kelvin. ${ }^{21}$

Predicted diffusion-limited hydrogen oxidation current densities.-In the dry $\mathrm{OCV} \mathrm{H}_{2}$-bleed experiments a mixture of argon, hydrogen and oxygen were used. To link the experimental condition and standard fuel cell operation with air, an additional computation for gas blend with nitrogen instead of argon was performed. Figure 7 


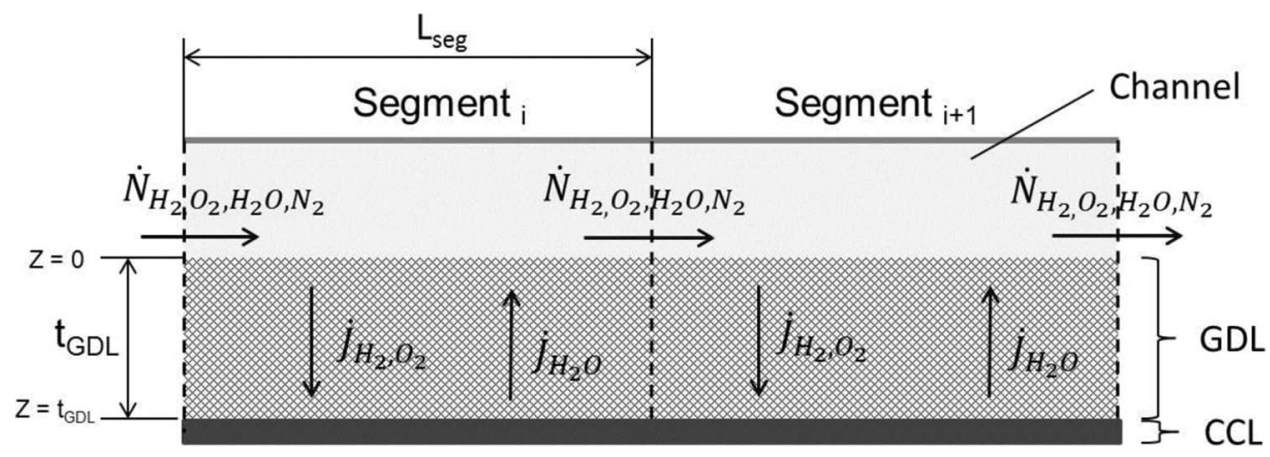

Figure 6. Along-the-channel model used for the computational simulations.

Table I. Molar balances used for the along-the-channel model (Figure 6), with $\dot{N}_{i}$ representing the along-the-channel molar flow rates and $\dot{J}_{i}$ :the though-plane molar fluxes.

Inlet conditions

$$
\begin{gathered}
\dot{N}_{\mathrm{H}_{2}, \text { inlet }}=\frac{\dot{N}_{\mathrm{O}_{2}+\dot{N}_{\mathrm{N}_{2}}} \cdot x_{\mathrm{H}_{2}}}{\left(1-x_{\mathrm{H}_{2}}\right)} \\
\dot{N}_{\mathrm{O}_{2}, \text { inlet }}=\lambda_{C} \cdot \frac{I}{4 \cdot F} \\
\dot{N}_{\mathrm{N}_{2}, \text { inlet }}=\lambda_{C} \cdot \frac{I}{4 \cdot F} \cdot\left(\frac{1-x_{\mathrm{O}_{2}}}{x_{O_{2}}}\right) \\
\dot{N}_{\mathrm{H}_{2} O, \text { inlet }}= \\
\left(\dot{N}_{\mathrm{O}_{2}}+\dot{N}_{N_{2}}+\dot{N}_{\mathrm{H}_{2}}\right)+\left(\frac{R H \cdot p_{\text {sat }}}{p-\left(R H \cdot p_{s a t}\right)}\right)
\end{gathered}
$$

Along-the-channel

$$
\begin{gathered}
\dot{N}_{H_{2}, i+1}= \\
\dot{N}_{H_{2}, i}-\dot{J}_{H_{2}, i} * A_{\text {seg }} \\
\dot{N}_{O_{2}, i+1}= \\
N_{O_{2}, i}-\dot{J}_{O_{2}, i} * A_{s e g} \\
\dot{N}_{N_{2}, i+1}=\dot{N}_{N_{2}, i} \\
\dot{N}_{H_{2} O, i+1}= \\
N_{H_{2} O, i}+\dot{J}_{H_{2}, i} * A_{s e g}
\end{gathered}
$$

shows the calculated diffusion-limited hydrogen oxidation current densities as a function of the hydrogen concentration in the channel for the dry $\mathrm{OCV}$ test operating conditions $\left(120^{\circ} \mathrm{C}, 18 \% \mathrm{RH}\right.$ and 150 $\mathrm{kPa}(\mathrm{abs}$.)). The diffusion-limited hydrogen current density is a strong function of the hydrogen concentration in the channel, reaching a value of $6.8 \mathrm{~A} \mathrm{~cm}^{-2}$ geo. under the dry $\mathrm{OCV}$ test conditions $\left(120^{\circ} \mathrm{C}\right.$, $18 \% \mathrm{RH}, 150 \mathrm{kPa}\left(\mathrm{abs}\right.$.), $4 \% \mathrm{H}_{2, \text { dry }}\left(\equiv 3.1 \% \mathrm{H}_{2 \text {,wet }}\right)$ ). If argon is replaced by nitrogen, the limiting hydrogen current is a little bit lower $\left(6.6 \mathrm{~A} \mathrm{~cm}^{-2}\right.$ geo $)$, but still in the same range.

Diffusion-limited hydrogen concentration profile along-thechannel.-Based on the above described model assumptions and equations, the gas concentrations and the diffusion-limited hydrogen flux can be calculated along-the-channel under the dry OCV conditions

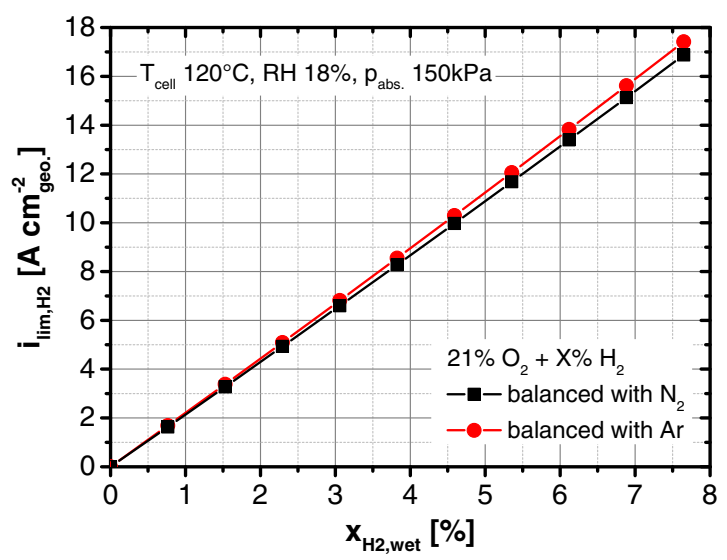

Figure 7. Calculated diffusion-limited hydrogen current densities $\left(\mathrm{i}_{\mathrm{lim}, \mathrm{H}_{2}}\right)$ for various hydrogen concentrations $\left(\mathrm{x}_{\mathrm{H}_{2} \text {,wet }}\right.$ ) in $21 \%$ oxygen (balanced with argon, red circular or balanced with nitrogen, black square) under the dry OCV test conditions of $120^{\circ} \mathrm{C}, 18 \% \mathrm{RH}$ and $150 \mathrm{kPa}(\mathrm{abs}$.). $\left(120^{\circ} \mathrm{C}, 18 \% \mathrm{RH}\right.$ at $100 \mathrm{sccm}$ cathode flow at $150 \mathrm{kPa}$ (abs.) with $4 \% \mathrm{H}_{2 \text {,dry }}\left(\equiv 3.1 \% \mathrm{H}_{2, \text { wet }}\right)$ ). Here a high hydrogen flux in the inlet region appears (see Figure 8) and, consequently, under diffusion-limited reaction conditions the hydrogen in the cathode feed would be completely consumed within the first $6 \mathrm{~mm}$ along-the-channel. Due to the negligible difference in limiting hydrogen current using argon or nitrogen as inert gas, a $\mathrm{H}_{2} / \mathrm{Ar}$ mixture is sufficient to use for the $\mathrm{H}_{2}$-bleed experiments.

Furthermore, the right axis of Figure 8 shows the produced heat for the diffusion-limited hydrogen oxidation. In the inlet region, the areal heat flux from the oxidation of hydrogen would be $\approx 8 \mathrm{~W} \mathrm{~cm}^{-2}$, which is higher than under normal fuel cell operation at full load (e.g., at $0.6 \mathrm{~V}$ at $2 \mathrm{~A} \mathrm{~cm}^{-2}$ geo, the areal heat flux would be $\approx 1.3 \mathrm{~W} \mathrm{~cm}^{-2}$ ). In summary, if one were to assume that the hydrogen oxidation kinetics at the cathode electrode are very fast and that the reaction would thus be diffusion-limited, the hydrogen from the $4 \% \mathrm{H}_{2 \text {,dry }}$-bleed into the cathode inlet would be consumed in a very narrow region near the inlet and would result in a roughly 6-fold higher areal heat flux near the entrance of the cathode flow-field at our dry OCV test conditions. Thus, if the hydrogen oxidation rate would be diffusion-controlled, one would expect substantially higher local temperatures near the cathode inlet, which might ultimately lead to localized membrane degradation and pin-hole formation. Whether this is indeed the case will be examined in the following.

MEA pin-hole distribution after the dry OCV test with and without $\boldsymbol{H}_{2}$-bleed.- - In order to determine whether MEA pin-holes after the dry $\mathrm{OCV}$ tests with $\mathrm{H}_{2}$-bleed into the cathode inlet were

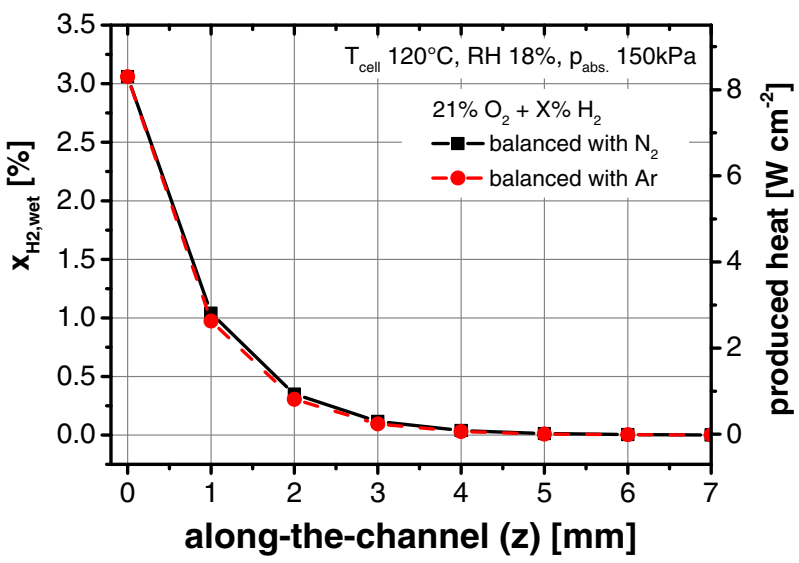

Figure 8. Calculated hydrogen concentration $\left(\mathrm{x}_{\mathrm{H}_{2} \text {,wet }}\right)$ in the channel (left side) and produced heat (right side) vs. channel length in the along-the-channel (based on $6 \mathrm{~mm}^{2}$ area segments) under the dry OCV conditions $\left(120^{\circ} \mathrm{C}, 18 \%\right.$

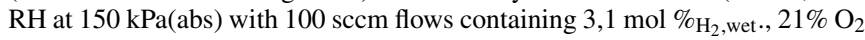
and balanced with argon, red circular or balanced with nitrogen, black square). 


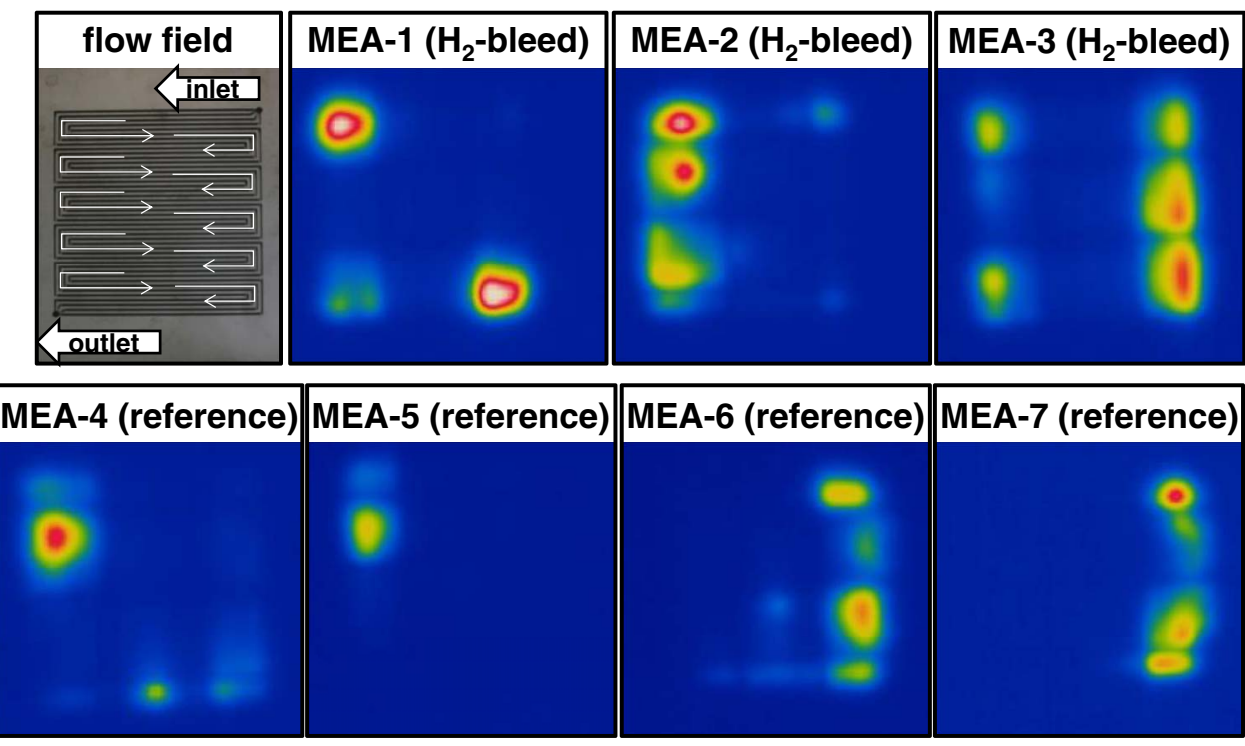

Figure 9. Flow-field geometry used for the $50 \mathrm{~cm}^{2}$ dry OCV tests (left-most panel in the top row) and infrared images showing the pin-hole distribution after the dry OCV tests for $\mathrm{H}_{2}$-bleed (MEA-1 to 3) and without $\mathrm{H}_{2}$-bleed (MEA-4 to 7) into the cathode feed. Blue areas indicate pin-hole free regions, while green to red areas indicate an increased size of pin-holes.

formed predominantly in the cathode inlet region, as would be expected if the $\mathrm{H}_{2}$ oxidation would be diffusion-controlled, we conducted a post-mortem pin-hole mapping analysis (see Experimental section) of all the MEAs after the dry OCV test. Figure 9 shows the ex-situ IR images for the various tested MEAs with $\mathrm{H}_{2}$-bleed (MEA-1 to 3 ) and without $\mathrm{H}_{2}$-bleed (MEA-4 to 7) into the cathode inlet during the dry OCV tests.

The colored infrared images in Figure 9 show the measured temperature differences across the MEAs, with blue areas indicating pin-hole free regions (i.e., no temperature increase), while green to red areas indicate an increasing temperatures derived from increasingly larger pin-holes. By comparing the infrared images of both experimental datasets (with and without $\mathrm{H}_{2}$-bleed), no systematic accumulation of pin-holes in the cathode inlet region of the flow-field can be discerned. In addition, pin-holes formed after the dry OCV test seem to be distributed randomly over the active area, without any preference for the cathode inlet region neither with nor without $\mathrm{H}_{2}$-bleed in the dry OCV test. This leads to the conclusion that the $\mathrm{H}_{2}$-bleed into the cathode feed does not seem to accelerate chemical degradation of the membrane, consistent with the observation that the extent of $\mathrm{H}_{2} \mathrm{O}_{2}$ formation is not affected by the $\mathrm{H}_{2}$-bleed (see Figure 2). The fact that pin-holes are not observed predominantly in the inlet region also suggests that the oxidation of hydrogen is likely not diffusion-limited, at least not under the conditions of the dry OCV test. Furthermore, the most pin-holes were detected in the edge areas of the MEA, independent, which is likely related to mechanical stress of the membrane at the perimeter of the active area, i.e., at the edge of the catalyst layer. These observations are consistent with the above described in-situ (Figure 4) and ex-situ (Figure 5) leak tests where also no differences were observed for MEAs operated with or without $\mathrm{H}_{2}$-bleed.

In summary, our analysis suggests that a $\mathrm{H}_{2}$-bleed into the cathode feed at the level of $\approx 4 \%$ does not seem to accelerate membrane degradation due to chemical or thermal effects. However it should be kept in mind that the dry OCV test does not include the possible impact of mechanical stresses caused by a potentially local RH-cycling in the inlet region, which could occur for fast hydrogen oxidation kinetics, as was shown by the above calculations for diffusion-limited hydrogen oxidation, in which case the areal heat flux near the cathode inlet could lead to temperature-cycles, and thus RH-cycles, when varying the $\mathrm{H}_{2}$-bleed rate. In this context, the effect of different locations for $\mathrm{H}_{2}$-bleed injecting (e.g. near the air exit) is also of interest and a potential option to reduce additional stress at the air inlet for real-world systems.

\section{Conclusions}

In conclusion, we have demonstrated that the bleeding of hydrogen into the cathode inlet does not lead to any additional hydrogen peroxide formation during the oxygen reduction reaction, as was shown by rotating ring disk electrode measurements performed with different $\mathrm{H}_{2} / \mathrm{O}_{2}$ gas mixtures. Furthermore, dry open circuit voltage membrane stability tests at $120^{\circ} \mathrm{C}$ and $18 \% \mathrm{RH}$ were conducted with and without $4 \% \mathrm{H}_{2}$-bleed into the cathode feed, clearly showing that the degradation of the membrane and the formation of membrane pin-holes were not affected by the $\mathrm{H}_{2}$-bleed.

A post-mortem MEA pin-hole distribution analysis showed no preference for pin-hole formation near the cathode inlet in the presence (or absence) of an $\mathrm{H}_{2}$-bleed, even though an along-the-channel model on the diffusion-controlled hydrogen oxidation rate at the cathode electrode showed that a substantially higher local temperature near the cathode inlet could occur under this assumption, which in turn would be expected to lead to very localized MEA failure near the cathode inlet in the presence of an $\mathrm{H}_{2}$-bleed.

Based on our findings, the bleeding of $\mathrm{H}_{2}$ into the cathode inlet up to 4 vol. \% is a promising approach, which could be used to reduce/prevent temporarily high hydrogen concentrations in the fuel cell exhaust during transient operation (e.g., start-up or fast transients). However, a mechanical degradation of the polymer membrane due to, e.g., local RH-cycling of the membrane induced by local hot-spots from hydrogen oxidation near the cathode inlet cannot be excluded and needs further investigation.

\section{Acknowledgments}

W. L. Gore \& Associates GmbH and SGL Carbon GmbH is acknowledged for supplying of MEA and GDL materials, the TEC Fuel Cell Crew (TU München) for support as well as the Volkswagen Group Research Fuel Cell team for fruitful discussions. This project was supported by the Volkswagen AG, Group Research Fuel Cell. 


\section{List of Symbols}

\begin{tabular}{|c|c|c|c|}
\hline Symbol & Parameter & Value & Unit \\
\hline$A$ & geometric area & & $\mathrm{cm}^{2}$ \\
\hline$c$ & $\begin{array}{l}\text { total molar concentration of all } \\
\text { species }\end{array}$ & - & $\mathrm{mol} \mathrm{m}^{-3}$ \\
\hline$c_{h}$ & channel height & 3 & $\mathrm{~mm}$ \\
\hline$c_{w}$ & channel width & 2 & $\mathrm{~mm}$ \\
\hline$D$ & diffusion coefficient & - & $\mathrm{cm}^{2} \mathrm{~s}^{-1}$ \\
\hline$D_{i j}$ & binary diffusion coefficient & - & $\mathrm{cm}^{2} \mathrm{~s}^{-1}$ \\
\hline$D_{e f f}$ & effective diffusion coefficient & - & $\mathrm{cm}^{2} \mathrm{~s}^{-1}$ \\
\hline$d$ & compressed thickness of the GDL & 150 & $\mu \mathrm{m}$ \\
\hline$F$ & Faraday constant & 96485.3 & $\mathrm{C} \mathrm{mol}^{-1}$ \\
\hline$I$ & current & - & A \\
\hline$i$ & current density & - & $\mathrm{A} \mathrm{cm}^{-2}$ \\
\hline$\dot{J}_{i}$ & flux of species $i$ through the GDL & - & $\operatorname{mol~s}{ }^{-1} \mathrm{~cm}^{-2}$ \\
\hline$L_{\text {seg }}$ & length of channel segment & 1 & $\mathrm{~mm}$ \\
\hline$M$ & molar mass & - & $\mathrm{g} \mathrm{mol}^{-1}$ \\
\hline$\dot{N}$ & molar flow rate & - & $\mathrm{mol} \mathrm{s}^{-1}$ \\
\hline$n_{c}$ & number of channels & 3 & - \\
\hline$P$ & pressure & - & $\mathrm{Pa}$ \\
\hline$R$ & ideal gas constant & 8.31451 & $\mathrm{~J}(\mathrm{~mol} \mathrm{~K})^{-1}$ \\
\hline RH & relative humidity & - & $\%$ \\
\hline$T^{*}$ & dimensionless temperature & - & - \\
\hline$t_{G D L}$ & compressed thickness of the GDL & 150 & $\mu \mathrm{m}$ \\
\hline$x_{i}$ & molar fraction of component $i$ & - & - \\
\hline \multicolumn{4}{|c|}{ Greek } \\
\hline$\varepsilon$ & porosity $^{19}$ & 0.66 & - \\
\hline$\varepsilon_{i j}$ & $\begin{array}{c}\text { characteristic Lennard-Jones } \\
\text { energy }\end{array}$ & - & $\mathrm{J}$ \\
\hline$k_{B}$ & Boltzmann constant & $1.38066 \cdot 10^{-23}$ & $\mathrm{~J} \mathrm{~K}^{-1}$ \\
\hline$\lambda_{i}$ & stoichiometry of reactant $i$ & 1.8 & - \\
\hline$\sigma_{i j}$ & $\begin{array}{c}\text { characteristic Lennard-Jones } \\
\text { length }\end{array}$ & & $\AA$ \\
\hline$\Omega_{i j}$ & collision integral & - & - \\
\hline
\end{tabular}

\section{References}

1. United Nations - Economic and Social Council, Proposal for a global technical regulation on hydrogen and fuel cell vehicles. 2013; Vol. ECE/TRANS/WP.29/ 2013/41.

2. E. Schießwohl, T. von Unwerth, F. Seyfried, and D. Brüggemann, Journal of Power Sources, 193(1), 107 (2009).

3. S. I. Kim, N. W. Lee, Y. S. Kim, and M. S. Kim, International Journal of Hydrogen Energy, 38(26), 11357 (2013).

4. S. I. Kim, K. D. Baik, B. J. Kim, N. W. Lee, and M. S. Kim, International Journal of Hydrogen Energy, 38(3), 1544 (2013).

5. C. M. Zalitis, D. Kramer, and A. R. Kucernak, Physical Chemistry Chemical Physics, 15(12), 4329 (2013).

6. A. Bonakdarpour, T. R. Dahn, R. T. Atanasoski, M. K. Debe, and J. R. Dahn, Electrochemical and Solid-State Letters, 11(11), B208 (2008).

7. S. Gottesfeld and J. Pafford, Journal of The Electrochemical Society, 135(10), 2651 (1988).

8. W. Wang, Journal of Power Sources, 191(2), 400 (2009).

9. H. A. Gasteiger, J. E. Panels, and S. G. Yan, Journal of Power Sources, 127(1-2), 162 (2004).

10. T. R. Ralph and M. P. Hogarth, Platinum Metal Rev., 3(46), 117 (2002).

11. M. Inaba, M. Sugishita, J. Wada, K. Matsuzawa, H. Yamada, and A. Tasaka, Journal of Power Sources, 178(2), 699 (2008).

12. K. C. Neyerlin, W. Gu, J. Jorne, and H. A. Gasteiger, Journal of The Electrochemical Society, 153(10), A1955 (2006).

13. J. Zhang, B. A. Litteer, F. D. Coms, and R. Makharia, Journal of The Electrochemical Society, 159(7), F287 (2012).

14. C. S. Gittleman, F. D. Coms, and Y.-H. Lai, Chapter 2 - Membrane Durability: Physical and Chemical Degradation A2 - Mench, Matthew M. In Polymer Electrolyte Fuel Cell Degradation, E. C. Kumbur; T. N. Veziroglu, Eds. Academic Press: Boston, 2012; pp 15.

15. F. D. Coms, H. Xu, T. McCallum, and C. Mittelsteadt, ECS Transactions, 64(3), 389 (2014).

16. R. Byron Bird, Warren E. Stewart, and E. N. Lightfoot, Transport Phenomena. 2007; Vol. Revised 2nd Edition.

17. Bruce E. Poling, John M. Prausnitz, and J. P. O'Connell, The Properties of Gases and Liquids. McGraw-Hill: New York, 2001; Vol. 5th Edition.

18. C. F. Curtiss and J. O. Hirschfelder, The Journal of Chemical Physics, 17(6), 550 (1949).

19. J. P. Owejan, T. A. Trabold, and M. M. Mench, International Journal of Heat and Mass Transfer, 71, 585 (2014).

20. D. A. G. Bruggeman, Annalen der Physik, 416(7), 636 (1935).

21. T. E. Springer, T. A. Zawodzinski, and S. Gottesfeld, Journal of The Electrochemical Society, 138(8), 2334 (1991). 